\title{
The Monetary Exchange Rate Model: Long-run, Short-run, and Forecasting Performance
}

\author{
Shidong Zhang \\ Washington State Department of Social and Health Services \\ Thomas C. Lowinger \\ Washington State University \\ Jie Tang \\ Economics Saint Martin's University
}

\begin{abstract}
This paper examines the monetary model of exchange rate determination for the US dollar exchange rates against the currencies of Canada, Japan, and the United Kingdom. In this paper, we utilize the cointegration technique for testing long-run relationship, and vector error correction model for short-run dynamics and out-ofsample forecasting. The existence of cointegration supports the long-run relationship among nominal exchange rate and a number of fundamental variables. The out-ofsample forecasting indicates that the nominal exchange rate forecasts from the VEC monetary model can be superior to random-walk based forecasts in a projection period of less than one year. This conclusion implies that the monetary model of exchange rate determination is a reliable tool for policy makers to evaluate their currency and the monetary authority should expect a much shortened response time to the monetary policy impulse in the surging trend of international economic integration.
\end{abstract}

\footnotetext{
*Corresponding address: Zhang, Shidong, Washington State Department of Social and Health Services Olympia, WA, 98504-5500, Phone: 360-725-1977, Fax: 360-753-9152, E-mail: zhangs@dshs.wa.gov, Lowinger, Thomas C., School of Economic Sciences Washington State University Pullman, WA, 99164-4741 Phone: 360-693-0556, Fax: 509-335-4362, Tang, Jie, Division of Business and Economics Sanit Martin's University 5300 Pacific Ave SE Lacey, WA 98503, E-mail: Jie.Tang@stmartin.edu 
- JEL classification: C53, F31, F41, F47

- Keywords: Exchange rate, Forecast, Monetary model, Cointegration, Vector error correction model

\section{Introduction}

After the collapse of the Bretton Woods monetary system in 1973, the exchange rates of industrialized nations were allowed to float freely. In response to this new institutional environment, the monetary approach to exchange rate determination was developed, refined, and empirically tested. The volatility of foreign exchange markets in the 1980s focused interest on exchange rate theory in general, and on the monetary approach in particular. However, attempts to replicate previous empirical results based on the new, more volatile data were unsuccessful. Moreover, the forecasting performance of the monetary model of exchange rate determination was shown to be no better, and sometimes even worse, than the predictions obtained by assuming that the spot exchange rate followed a random walk.

In their influential paper, Meese and Rogoff (1983) compared the out-of-sample forecasting accuracy of various structural and time series exchange rate models. They concluded that the random walk model performed as well as any estimated model for one to twelve month horizons for the dollar/pound, dollar/mark, dollar/ yen and the trade-weighted dollar exchange rate. The structural models included in their study were the flexible price model, the sticky price monetary model, and the sticky price model that incorporated the current account. Two of the possible reasons for the poor out-of-sample fit, noted by Meese and Rogoff, were the failure of uncovered interest parity and misspecification of the monetary model. On the other hand, Meese and Rogoff concluded that when one considers forecast horizons longer than one year, the performance of the monetary exchange rate model appears to improve. They also observed that the root mean squared forecast errors for the random walk model were no longer consistently the lowest, when one considers two- to three-year forecast horizons.

The monetary model did not escape the Meese and Rogoff trap that seemingly ensnared all other models of exchange rate determination. While considerable research was done on both the theoretical models and on empirical testing of certain propositions of exchange rate determination, little success was attained until Mark (1995) rekindled the interest in the monetary model as a long run relationship. 
Subsequent studies by Groen (2000), Mark and Sul (2001), and Rapach and Wohar (2001) obtained evidence in support of the monetary model, especially in the long run.

Given the availability of more data, this paper seeks to re-examine the monetary model of exchange rate determination using a multivariate time series methodology to find out whether the long run relationship between the nominal exchange rate and various fundamental variables still holds, and significantly to determine whether the out-of-sample forecasting performance of the monetary model can outperform the random walk model, especially in the short-run.

\section{The Monetary Model}

The monetary model asserts that exchange rates are the relative prices of assets, determined in organized markets where prices can adjust instantaneously. One important assumption of the monetary model is that the purchasing power parity (PPP) holds continuously over time, which is well established as a long-run relationship, although the half-lives seems longer than expected (Rogoff (1996), and Papell (1997)). The PPP relationship can be expressed as follows:

$$
s_{t}=p_{t}-p_{t}^{*}+c+\varepsilon_{t}
$$

where $\mathrm{c}$ is a constant, $\mathrm{s}_{\mathrm{t}}$ is the logarithm of the exchange rate expressed in units of home currency per foreign currency unit, $p_{t}$ and $p_{t}{ }^{*}$ are the domestic and foreign price levels, respectively, and $\varepsilon_{t}$ is an error term, which follows a stationary process. If $\mathrm{c}=0$, Equation (1) implies an absolute PPP relationship, and if $c \neq 0$, Equation (1) implies that the relative PPP holds.

The second cornerstone of the monetary model assumes a stable monetary demand function in the domestic and foreign countries. The money market equilibrium condition in both domestic and foreign countries is assumed to depend on the logarithm of real income (y), the logarithm of the price level (p), and the nominal interest rate (i). A similar relationship is assumed to hold for the foreign country, where foreign variables are denoted by asterisk. The monetary equilibrium in both domestic and foreign countries can be expressed as:

$$
\begin{gathered}
m_{t}=p_{t}+\beta_{2} y_{t}-\beta_{3} i_{t}+\mu_{t} \\
m_{t}{ }^{*}=p_{t}{ }^{*}+\beta_{2}^{*}{ }_{2}{ }^{*}{ }_{\mathrm{t}}-\beta_{3}{ }_{3} i_{\mathrm{t}}{ }^{*}+\mu_{t}{ }^{*}
\end{gathered}
$$


where $m_{t}$ and $m_{t}^{*}$ denote the domestic and foreign money demand in logarithm, and are assumed in equilibrium to be equal to their respective money supplies; $\beta_{2}$ and $\beta_{2}^{*}$ are the income elasticity of demand for money, $\beta_{3}$ and $\beta_{3}^{*}$ are the interest rate semi-elasticity for the domestic and foreign countries, and $\mu_{t}$ and $\mu_{t}^{*}$ are error terms, respectively. Rearranging equations (3) and (4) and solving for the domestic and foreign price levels and substituting into equation (1) yields the flexible price monetary model of the exchange rate:

$$
s_{t}=m_{t}-m_{t}^{*}-\beta_{2} y_{t}+\beta_{2}^{*} y_{t}^{*}+\beta_{3} i-\beta_{3}^{*} i_{t}^{*}+c+\varepsilon_{t}^{*}
$$

where $\beta s$ are parameters stated above, $\mathrm{c}$ is an arbitrary constant, and $\varepsilon_{t}^{*}$ is a disturbance term.

Considering the importance of the interest rate in the real world international financial market and the possible failure of the uncovered interest parity, Equation (5) does not include the uncovered interest parity condition. Moreover, Equation (5) does not follow the common practice of assuming that the economic structure of the foreign country is the same as that of the home country (i.e. $\beta_{i} \neq \beta_{i}^{*}$ ).

\section{Methodology and Data}

The purpose of this study is two-fold. First, we want to establish the empirical validity of the monetary model of exchange rate determination. Second, we want to determine whether the forecasts based on the monetary model outperforms the random walk. The cointegration and vector error-correction model (VECM) methods are utilized in this paper to examine the relationships between the exchange rate and various economic fundamental variables.

Countries included in this study are Canada, Japan, the United Kingdom, and the United States. These countries are the largest economic entities among those whose foreign exchange arrangements are classified as independently floating by International Monetary Fund. Independently floating means that the exchange rate is market-determined. The data used are quarterly, seasonally adjusted data from the International Monetary Fund (IMF)'s International financial statistics. The time horizon chosen is from the first quarter of 1975 to the last quarter of 2004. The data used in the modeling are as follows:

$\mathrm{s}_{\mathrm{t}}$ : The market rate of a foreign currency per US dollar, in logarithm;

$\mathrm{y}_{\mathrm{t}}$ : Gross domestic product (GDP) in national currency, in logarithm; 
$\mathrm{i}_{\mathrm{t}}$ : Short term money market interest rate (federal funds rate for the US dollar); $\mathrm{m}_{\mathrm{t}}$ : Seasonally adjusted M1 in national currency, in logarithm;

$\mathrm{p}_{\mathrm{t}}$ : Consumer Price Index (CPI), in logarithm.

The United States is chosen as the home country and Canada, Japan, and United Kingdom were selected for the foreign countries. US dollar is selected as the base currency. Therefore, three pairs of countries, namely, Canada/US, Japan/US, and $\mathrm{UK} / \mathrm{US}$, were chosen to test the relationship suggested by the monetary exchange rate model.

\section{Empirical Results}

The cointegration technique allows for the estimation of a long run equilibrium relationship based on the monetary model of the exchange rate determination. Simply put, one can argue that various non-stationary time series are said to be cointegrated when their linear combinations are stationary. Stationary deviations from the long run relationship are permitted in the short run. The cointegration technique was pioneered by Engle and Granger (1987), and extended by Johansen (1988), and Johansen and Juselius (1990).

Cointegration is a relationship among non-stationary variables. Consistent with previous studies, the Augmented Dickey-Fuller and Phillips-Perron tests suggest that all of the univariate variables in Equation (5) for all the countries are nonstationary, and follow $\mathrm{I}(1)$ processes. Hence, we can consider a 6-dimensional vector $Z_{t}=\left(s_{t}, m_{t}-m_{t}^{*}, y_{\mathrm{t}}, y_{t}^{*}, i_{t}, i_{t}^{*}\right)$ for the cointegration test.

For the cointegration test, the following null hypothesis was tested:

$$
H_{0}: \Pi Z_{t-1}=\alpha\left(\beta^{\prime} Z_{t-1}+\rho\right)+\delta
$$

where $\alpha$ and $\beta$ are $\mathrm{m} \times \mathrm{r}$ matrices. $\mathrm{m}$ is 6 , and $\mathrm{r}$ is the number of cointegrating relations conditional on the assumptions made about the trend.

The reason for choosing proposition (6) is:

1. As in Equation (5), the cointegrating relationships should include a constant term;

2. From the data, we can clearly make out an upward trend or a downward trend for variables except the nominal interest rates.

The Johansen cointegration test is sensitive to the choice of lag length while the Akaike Information Criterion (AIC) can be used to determine the most appropriate 
lag length. Two tests, namely, the maximum eigenvalue test and the trace test are used to test the cointegrating relationship. The results are shown in Table 1. For three cases tested, both the maximum eigenvalue test and the trace test indicate that there exist a cointegration relationship between the nominal exchange rate and various fundamental variables.

In empirical exchange rate economics, forecasting contests are important in evaluating the theoretical models, as the link between in-sample criteria and forecasting performance are far from obvious. Our forecasts are based on the vector error correction (VEC) model. A vector error correction model is a restricted form of the vector autoregression model (VAR) designed for using non-stationary series, so that it only applies to cointegrated series. The VEC model restricts the long-run behavior of the endogenous variables to converge to their cointegrating relationships while allowing for their short-run adjustment dynamics. To gain insight into how the long-run equilibrium between nominal exchange rates and monetary fundamentals is determined, we estimate the following VEC model:

$$
W_{t}=\delta+\Phi Z_{t-1}+\sum_{i=1}^{p-1} \Phi_{i} W_{t-1}+\varepsilon_{i}
$$

where $Z_{t}=\left(s_{t}, m_{t}-m^{*}, y_{t}, y^{*}{ }_{t}, i_{t}, i_{t}{ }^{*}\right), W_{t}=Z_{t}-Z_{t-1}$, and $\Phi$ and $\Phi_{i}$ are coefficient matrices, while $\mathrm{p}$ is the lag length. The long-run behavior of $Z_{t}$ is based on the coefficient matrix $\Phi$ and the cointegrating rank is decided by the rank of $\Phi$. By using the cointegrating ranks of Table 1, and the methodology of Johansen (1988, 1991) and Johansen and Juselius (1990), we can estimate $\Phi$ and $\Phi_{i}$ and thus obtain the dynamic short-run forecasts.

The time horizon used in estimating the VEC model ranges from the first quarter of 1975 to the last quarter of 2002. Similar to the cointegration tests, choosing an appropriate lag length is important in estimating the VEC model. The choice of the lag length is based on the adjusted log likelihood and AIC. For Canada/US exchange rate, the lag length chosen is 13 (quarters), for Japan/US exchange rate, it is 8 (quarters), and for UK/US exchange rate, it is chosen as 12 (quarters). After

Table 1. The Cointegration test results at 0.01 significance level

\begin{tabular}{lccc}
\hline & Canada/US & Japan/US & UK/US \\
\hline Lags & 6 & 9 & 7 \\
Maximum Eigenvalue Test & 4 & 4 & 3 \\
Trace Test & 4 & 4 & 3 \\
\hline
\end{tabular}


estimating the VEC model from data ranging from 1975.1 to 2002.4, the estimated exchange rate Equation (7) was used to forecast the exchange rate for eight forecasting horizons, namely, 3, 6, 9, .,24 months forward over the period from 2003.1 to 2004.4. The forecasted values and the realized values are listed in Table 2, and plotted in Figure 1.

Next, we utilize the root mean square error (RMSE) to evaluate the out-ofsample performance of the forecasting model, which is defined as follows:

Root Mean Square Error (RMSE): $\left\{\sum_{S=0}^{N_{k}-1}\left[F\left(t_{0}+s\right)-A\left(t_{0}+s\right)\right] / N_{k}\right\}^{1 / 2}$

Table 2. Comparison of realized log exchange rate and forecasted log exchange rate value

\begin{tabular}{ccccccc}
\hline OBS & CA/US & $\mathrm{F}(\mathrm{CA} / \mathrm{US})^{*}$ & $\mathrm{JP} / \mathrm{US}$ & $\mathrm{F}(\mathrm{JP} / \mathrm{US})^{*}$ & $\mathrm{UK} / \mathrm{US}$ & $\mathrm{F}(\mathrm{UK} / \mathrm{US})^{*}$ \\
\hline $2003: 1$ & 0.384786 & 0.3659523 & 4.788741 & 4.733479 & 0.45723496 & 0.5878273 \\
$2003: 2$ & 0.304023 & 0.3230234 & 4.786241 & 4.843416 & 0.50083589 & 0.5237675 \\
$2003: 3$ & 0.300401 & 0.3621451 & 4.7113304 & 4.85381 & 0.51497699 & 0.5348955 \\
$2003: 4$ & 0.256501 & 0.3183646 & 4.673763 & 4.68264 & 0.57925033 & 0.6192184 \\
$2004: 1$ & 0.270409 & 0.2467518 & 4.6472714 & 4.615432 & 0.60671745 & 0.5783006 \\
$2004: 2$ & 0.292968 & 0.2581765 & 4.6856436 & 4.635597 & 0.59426563 & 0.5626074 \\
$2004: 3$ & 0.234202 & 0.2454114 & 4.7095302 & 4.644729 & 0.58711978 & 0.5674629 \\
$2004: 4$ & 0.185317 & 0.1941196 & 4.6455441 & 4.603596 & 0.65824513 & 0.5757329 \\
\hline
\end{tabular}

*F(.) means the forecasted log exchange rate.

Fig. 1. Forecasts and realized data
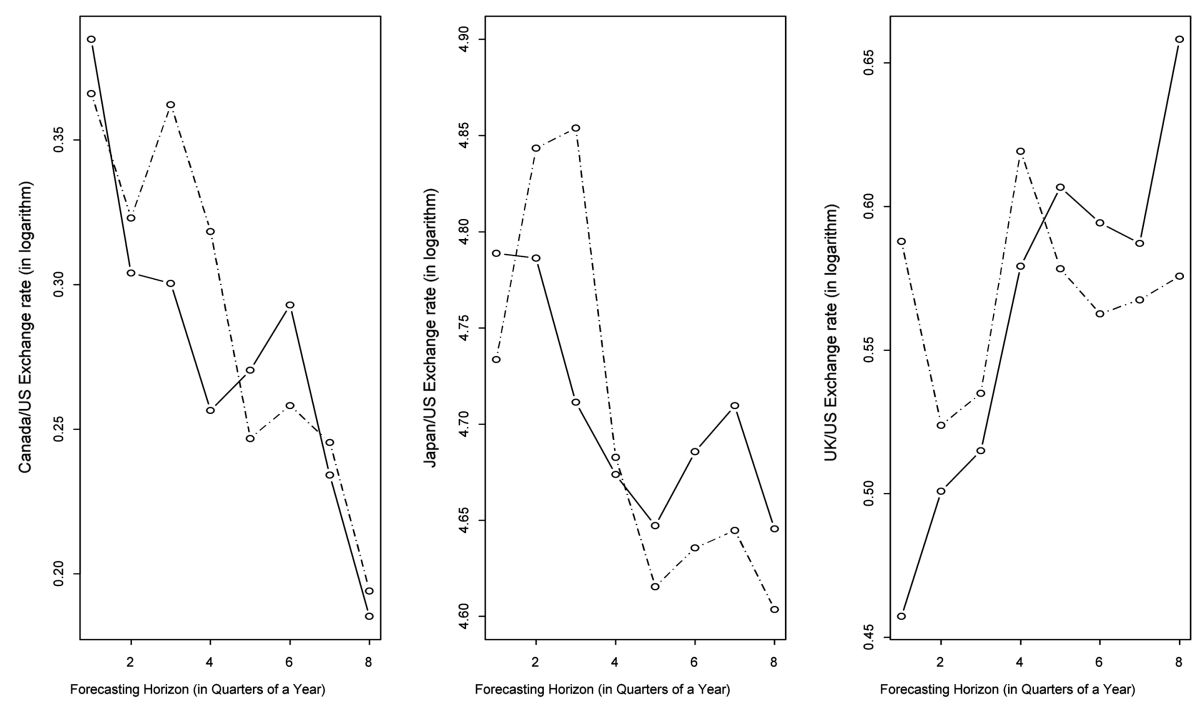
Where $N_{k}$ denotes the total number of forecasts in the projection period for which the actual $A(t)$ is the realized exchange rate value in logarithm, and $F(t)$ is the out-of-sample forecasting value. To find out whether the out-of-sample exchange rate forecast based on the monetary VEC model outperforms the forecasts based on the random walk, we calculate the RMSE ratio between them with the RMSE of the random walk given as the numerator. We then simulate the random walk based forecasts for 1 million times to obtain the probability of the monetary exchange rate model outperforming the random walk (the percentage of the RMSE ratio $>1$ ). The results are shown in Table 3.

As shown in Table 3, for a projection period of less than 6 months, no clear evidence exists that the monetary model outperforms the random walk. However, for a longer time period, the performance of the monetary model is superior and finally we find strong evidence that the monetary exchange rate model outperforms the random walk for forecasts beyond 9 months. These results are consistent with Meese and Rogoff (1983), Mark (1995) and Chinn and Meese (1995) that the monetary model is correspond to a longer time horizon relationship. Moreover, our results suggest that the monetary model can outperform the random walk for a time horizon of less than one year, which therefore favors the monetary model.

\section{Conclusion}

In this paper we investigate the monetary model of exchange rate determination by applying a multivariate time series model of the US dollar exchange rates to the Canadian dollar, Japanese Yen, and United Kingdom's pound. The existence of cointegration between exchange rate and various fundamental variables supports the monetary model as a long run relationship. Moreover, the out-of-sample dynamic forecasts from the VEC model outperform the random walk forecasts for a time horizon of less than 12 months rather than two to three years, which suggests that the monetary model of exchange rate determination is a reliable tool for policy makers to evaluate their currency. These conclusions also imply that to

Table 3. Probability of monetary model outperforms random walk

\begin{tabular}{ccccccccc}
\hline & $2003: 1$ & $2003: 2$ & $2003: 3$ & $2003: 4$ & $2004: 1$ & $2004: 2$ & $2004: 3$ & $2004: 4$ \\
\hline Canada./US & 0.018 & 0.845 & 0.951 & 0.941 & 0.995 & 0.991 & 0.999 & 0.938 \\
Japan/US & 0.371 & 0.490 & 0.217 & 0.999 & 0.994 & 0.933 & 0.825 & 0.992 \\
UK/US & 0.992 & 1.000 & 0.999 & 1.000 & 1.000 & 1.000 & 1.000 & 1.000 \\
\hline
\end{tabular}


the monetary authority of an open economy with independently floating foreign exchange regime, the expansion of the monetary base still constitutes effective monetary policy. Nonetheless, monetary policy through the interest rate channel and the exchange rate channel are still effective. The three most noted intermediate monetary policy targets, namely interest rates, monetary aggregates, and exchange rates, are interrelated and a successful monetary policy should work with a mix of targets, keeping an eye on interest rates, monetary aggregates, and exchange rates at the same time. Moreover, the exchange rate monetary policy channel and the exchange rate monetary policy targets become increasingly important with the integration of the global economy. This can be explained by the more quickly capital movement across countries and the more expanded international trade. The monetary authority should expect a much shortened response time to the monetary policy impulse in the surging trend of international economic integration.

Received 15 June 2006, Accepted 9 October 2006

\section{References}

Chinn, Menzie and Richard Meese, (1995), "Banking on Currency Forecasts: How Predictable is Change in Money?" Journal of International Economics 38, 161-178.

Engle, Richard and Clive Granger,(1987), "Co-integration and error correction: Representation, estimation, and testing", Econometrica 55, 251-276.

Groen, Jan (2000), "The Monetary Exchange Rate Model as a Long-Run Phenomenon", Journal of International Economics 52, 299-319.

Johansen, Soren (1988), "Statistical Analysis of Cointegration Vectors", Journal of Economic Dynamics and Control, Volume 12, Pages 231-254.

Johansen, Soren and Juselius, Katarina (1990), "Maximum Likelihood Estimation and Inference on Cointegration-with Application to the Demand for Money", Oxford Bulletin of Economics and Statistics, Volume 52, Pages 169-210.

Johansen, Soren (1991), "Estimation and Hypothesis Testing of Cointegration Vectors in Gaussian Vector Autoregressive Models", Econometrica, Volume 59, Issue 6, Pages 1551-1580.

Mark, Nelson (1995), "Exchange rates and fundamentals: evidence on long-horizon Predictability", American Economic Review, Volume 85 (March), Pages 201-218.

Mark, Nelson and Sul, Donggyu (2001), "Nominal Exchange Rates and Monetary Fundamentals: Evidence from a Small Post-Bretton Woods Panel", Journal of International Economics, Volume 53, Pages 29-52.

Meese, Ricard and Rogoff, Kenneth (1983), "Empirical Exchange Rate Models of the Seventies: Do They Fit Out of Sample?" Journal of International Economics, 
Volume 14 (1983), Pages 3-24.

Papell, David (1997), "Searching for Stationarity: Purchasing Power Parity under the

Current Float," Journal of International Economics, November 1997, 313-332.

Rapach, David and Wohar, Mark (2001), "Testing the Monetary Model of Exchange Rate Determination: New Evidence from a Century of Data." Journal of International

Economics, Volume 58, Number 2, Pages 359-385.

Rogoff, Kenneth (1996), "The Purchasing Power Parity Puzzle," Journal of Economic Literature, XXXIV, 1996, 647-668. 